\title{
PROPOSTA DE UM SISTEMA DE SUPORTE EXECUTIVO PARA MICRO E PEQUENAS EMPRESAS FUNDAMENTADO NO MODELO CAMPOS E ARMAS DA COMPETIÇÃO
}

\section{PROPOSAL OF AN EXECUTIVE SUPPORT SYSTEM FOR SMALL BUSINESS BASED ON FIELS AND WEAPONS OF COMPETITION}

\author{
Luciano Silva Gomes* luciano.gomes@nossacaixa.com.br \\ * Universidade Metodista de Piracicaba (UNIMEP)
}

\begin{abstract}
Resumo: Este artigo objetiva apresentar uma proposta de SSE (Sistema de Suporte Executivo) para orientar a formulação de estratégias competitivas para MPE's (Micro e Pequenas Empresas). Para isso, utilizou-se os métodos de pesquisa bibliográfica, por meio do estudo da dissertação de Gomes (2007), que especificou um SI (Sistema de Informação) para formulação de estratégias competitivas através do modelo CAC (Campos e Armas da Competição), de Contador (1996), além da engenharia de software para projetar o sistema proposto. Neste trabalho foi constatado que administração estratégica nessas empresas não ocorre de um modo estruturado. Com o objetivo de formalizar este tipo de administração nestas empresas, caracterizando o problema desta pesquisa, este artigo contribui ao projetar um sistema de nível estratégico através da apresentação dos requisitos e funcionalidades necessários para o desenvolvimento de um sistema computacional.
\end{abstract}

Palavras-chave: Micro e Pequenas Empresas, Tecnologia da Informação, Sistemas de Informação, Estratégia, Campos e Armas da Competição.

Abstract: This paper presents a proposal of a solution, specifically an ESS (Executive Support System) to guide the formulation of competitive strategies for small business. For this, was used the methods of research literature by studying the dissertation of Gomes (2007) which specified a IS (Information System) to formulate competitive strategies based on the Fields and Weapons Competition model, of Contador (1996), in addition to software engineering to design the proposed system. In this dissertation it was found that strategic management in small business does not occur in a structured manner. Aiming to formalize this type of management in the small business, characterizing the problem of this research, this paper contributes to the design a system of strategic level, presenting the requirements and functionality required for the development of a computer system.

Key-words: Small Business, Information Technology, Information Systems, Strategy, Fields and Weapons of the Competition.

\section{INTRODUÇÃO}

O objetivo deste trabalho é propor o desenvolvimento de um SSE para MPE's as quais, segundo informações de Gomes (2007), representavam a maior parte das empresas estabelecidas no Brasil, empregando mais da metade da mão-de-obra 
brasileira, respondendo por parte significativa do PIB (Produto Interno Bruto). O critério, estabelecido pelo Estatuto da MPE, utilizado para distinguir o tamanho de uma empresa é o seu faturamento bruto anual, o qual é apresentado na Tabela 1.

Tabela 1 - Caracterização do Porte da Empresa.

\begin{tabular}{|l|l|c|}
\hline & \multicolumn{1}{|c|}{ Micro empresa } & Pequena empresa \\
\hline $\begin{array}{l}\text { Faturamento } \\
\text { bruto anual }(\mathbf{R} \$)\end{array}$ & Menos de 433.755,15. & De 433.755,16 até 2.133.222,00 \\
\hline
\end{tabular}

Fonte: Adaptado de Gomes (2007).

Em seu trabalho, Gomes (2007) verificou que 60\% das empresas deste porte não "sobrevivem" mais que cinco anos e quase um terço dessas encerram suas atividades depois de 12 meses de funcionamento.

Vários fatores são considerados cruciais para sobrevivência das MPE's e um deles é o aspecto estratégico. Nestas empresas, a administração estratégica não ocorre de um modo estruturado, pois falta conhecimento por parte dos seus gestores sobre as ferramentas para este tipo de gestão. Além disso, estes estão muito comprometidos com a operação do empreendimento para poderem despender seu tempo a fim de adquirir conhecimento sobre essas práticas de gestão e implementarem em suas empresas (GOMES, 2007).

Segundo Betim et al (2005), as MPE's possuem dificuldades para implementação de recursos de TI, pois elas não comportam, em sua estrutura organizacional, profissionais dedicados a esta área. Algumas das vantagens na utilização da TI, por essas empresas, poderiam ser: melhorar as informações para tomar decisões; auxiliar os gestores a testar alternativas de decisões antes de colocá-las em prática e aumentar a competitividade da empresa.

Para Zanon e Filho (2008), uma estratégia de operação deve-se basear em sistemas que proporcionem um rápido balanceamento das estratégias competitivas, respondendo a tempo as frequentes mudanças no ambiente. A percepção destas prioridades pelos membros da empresa é o ponto principal para o sucesso do alinhamento estratégico de sua operação.

Com isso, a contribuição deste trabalho consiste na apresentação dos requisitos funcionais para o desenvolvimento de um SSE automatizado, o qual deve 
orientar a formulação de alternativas de estratégias competitivas para MPE's de um modo estruturado, sendo este de fácil aprendizado, manuseio, que subsidiem de maneira rápida as decisões dos gestores. Sua justificativa baseia-se nos seguintes fatos apresentados: a estratégia ser importante para a sobrevivência da MPE, pois essas não possuem uma cultura de administração estratégica e de utilização da TI.

Um SSE consiste em um SI, o qual engloba um conjunto de partes envolvendo softwares, hardwares, recursos humanos e procedimentos, que produzem informações. O principal objetivo desse tipo de SI é apoiar o processo de tomada de decisões (REZENDE, 2002). Por sua vez, a administração estratégica baseia-se nas teorias e ferramentas para formulação e gestão de estratégias, as quais são projetadas para os dirigentes pensarem e decidirem sobre qual é a ideal. Uma dessas ferramentas é o MCAC, utilizado como fundamentação do SSE proposto que, segundo Contador (2008), é adequado, capaz e suficiente para analisar as formas usadas pelas empresas para competir, identificar e analisar suas estratégias competitivas, explicar os fatores determinantes da sua competitividade, recomendar medidas destinadas à ampliação da sua competitividade e formular suas estratégias competitivas.

\section{METODOLOGIA}

Para desenvolver o SSE, foi necessário seguir um método para auxiliar o seu projeto. O método que vêm a guiar o projeto do sistema proposto foi o da engenharia de software, através do modelo de ciclo de vida, o qual foi utilizado para conceitos e seus requisitos necessários na bibliografia, utilizando a metodologia de pesquisa bibliográfica, que segundo Macedo (1994), consiste na busca de informações para resolução de problemas relacionados a pesquisa através da seleção de referenciais teóricos publicados.

\subsection{Modelo de ciclo de vida clássico}

O modelo de vida clássico, também conhecido como modelo cascata, abrange as seguintes atividades: 1. Análise e especificação de requisitos; 2. Projeto; 
3. Implementação e teste unitário; 4. Integração e teste do sistema; e 5. Operação e Manutenção. A seguir será ilustrado como ocorre à interação entre estas fases (CARVALHO ET AL, 2007).

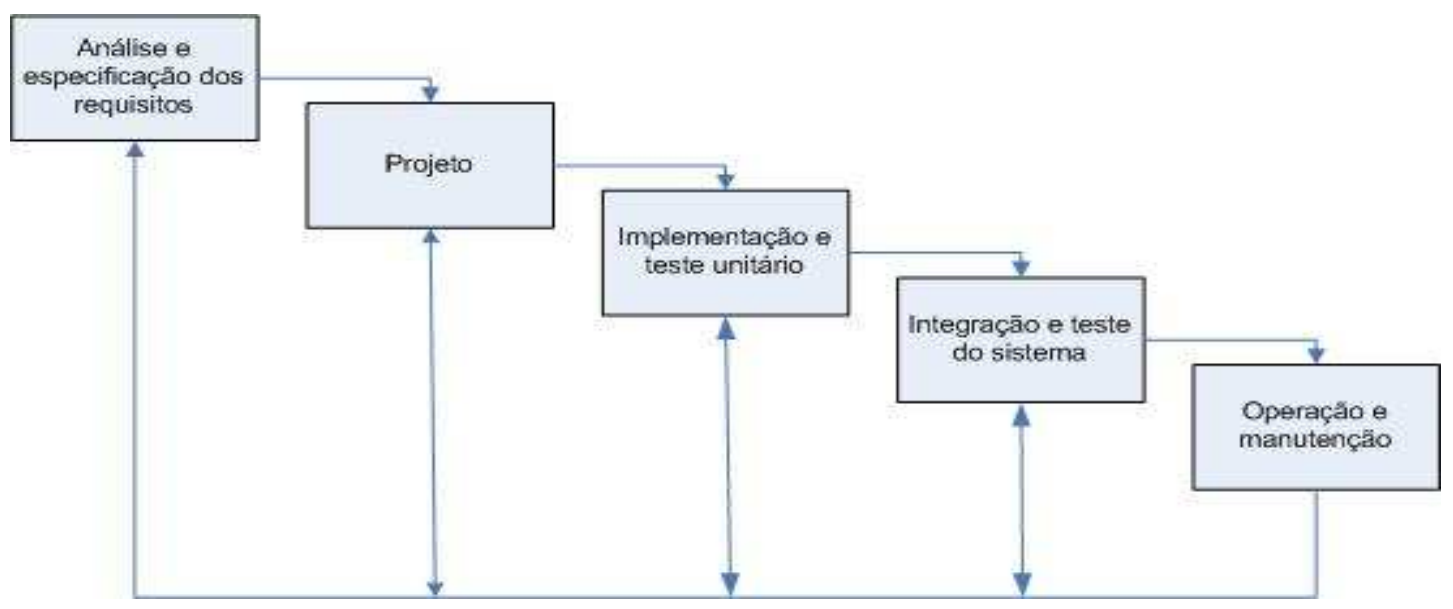

Figura 1 - O ciclo de vida clássico

Fonte: Carvalho et al (2007)

$\mathrm{Na}$ atividade de análise e especificação dos requisitos funcionais e nãofuncionais são identificadas, através de consultas com o cliente, as funcionalidades a serem executadas pelo sistema. $O$ desenvolvedor deve especificar requisitos que o sistema deve possuir. $O$ resultado dessa fase é um documento de especificação, o qual será o instrumento de comunicação entre os indivíduos envolvidos na implementação do sistema. Ele deve ser facilmente modificável, pois deve evoluir para acomodar a natureza evolutiva do sistema.

O projeto do sistema consiste em um processo de várias etapas que se baseiam em quatro atributos distintos: "estrutura de dados, arquitetura do software, detalhes procedimentais e caracterização da interface" (PRESSMAN, 1995).

$\mathrm{Na}$ atividade de implementação e teste unitário o projeto é "traduzido" para a linguagem de computador. Esta fase é conhecida como programação. $O$ teste unitário visa verificar se cada unidade implementada satisfaz suas especificações.

$\mathrm{Na}$ atividade de integração e teste do sistema, os programas ou unidades de programa são integrados e testados como um sistema completo, visando garantir que todos os seus requisitos sejam satisfeitos. Depois de testado, o produto é entregue ao usuário. 
$\mathrm{Na}$ atividade de operação e manutenção o produto é instalado e colocado em uso. A manutenção é a atividade executada depois que o produto é entregue e consiste na correção de erros não descobertos nas atividades de testes. Além disso, ela abrange as fases de adaptação às mudanças do ambiente e de mudanças nos requisitos.

\subsection{Procedimentos}

O modelo de administração estratégica, utilizado para especificar os requisitos funcionais da solução proposta, foi o MCAC, que é um modelo de formulação estruturada de estratégias competitivas, "de fácil entendimento", segundo Contador (1996). Os procedimentos utilizados para sua especificação foram os seguintes:

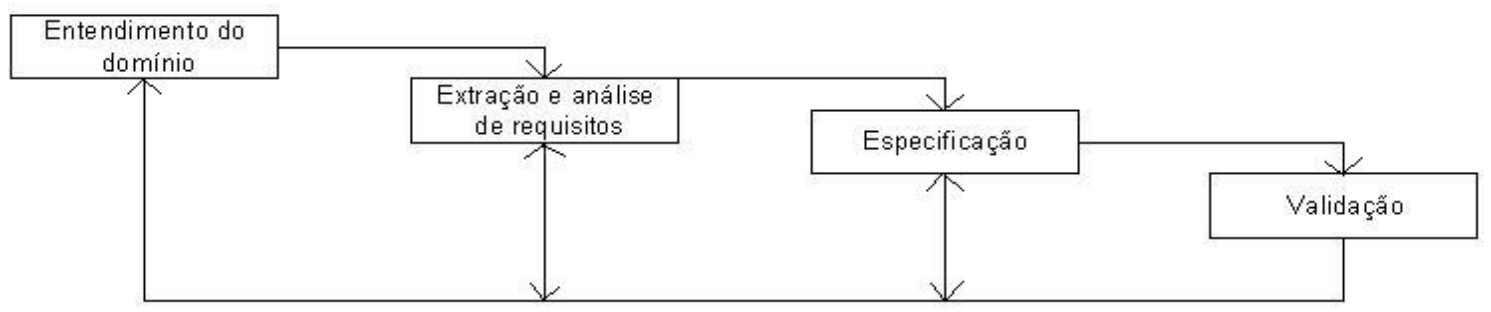

Figura 2 - Procedimentos de extração de requisitos Fonte: Carvalho et al (2007)

- Entendimento do domínio: para qual finalidade deve ser aplicada o sistema. Neste caso, para formulação estruturada de alternativas de estratégias competitivas, suportando as decisões dos gestores de MPE's.

- Extração e análise de requisitos: nessa fase se descobre, revela e entende os requisitos, os quais foram extraídos do MCAC e de entrevistas com o seu idealizador.

- Especificação dos requisitos: armazenam-se os requisitos em linguagem natural, formal ou semi-formal, apresentando as funcionalidades necessárias a serem realizadas pelo sistema que, no caso deste trabalho, são apresentadas no item 3.

- Validação dos requisitos: verifica se os requisitos atendem as necessidades dos seus futuros usuários. Segundo Contador (2008), o MCAC já foi aplicado 
de modo satisfatório em diversas organizações comerciais, industriais e de serviços para formulação estruturada de estratégias competitivas, além de existirem diversos estudos acadêmicos embasados neste modelo.

\section{REVISÃO BIBLIOGRÁFICA}

Segundo Laudon e Laudon (2001), um SI pode ser classificado de acordo com a responsabilidade assumida por seus usuários. Um SSE é um sistema de nível estratégico destinado a decisões estratégicas, que apóia à alta gerência em atividades como a formulação de uma estratégia, conforme explicado no subitem 2.1. Ele é capaz de responder à perguntas específicas, fazer projeções e simulações, sendo caracterizado pela manipulação de dados quantitativos e qualitativos. Além disso, oferece um alto grau de especialização, suportando todos os aspectos para a tomada de decisões estruturadas. Ou seja, um SSE deve ser projetado para resolver problemas específicos (SILVA, 2009).

\subsection{Estratégia e seu processo de formulação}

Segundo Mintzberg (1983), a estratégia é entendida como uma adaptação entre um ambiente dinâmico e um sistema de operações estável, ajustando-se continuamente. Swamidass e Newell (1987) definem estratégias como ações voltadas para realização dos objetivos da organização. Na visão de Contador (2008), autor do MCAC apresentado no subitem 2.1.1, "estratégia é a criação de uma posição exclusiva e valiosa, traduzida na escolha de um conjunto diferente de atividades com o fim de entregar um composto de valor único para o cliente, marcando uma posição estratégica."

As estratégias podem ser divididas em três níveis: corporativa (relativa à corporação, constituída por um conjunto de empresas), negócio (relativa a uma empresa ou a uma unidade de negócio, para posicionamento de produto no mercado) e funcionais ou operacionais (relativas às várias áreas funcionais ou departamentos da empresa). Outro nível citado por Kotha e Orne (1989) é o da 
indústria (relativa à política da indústria, tais como incentivos, barreiras, inflação, infra-estrutura, regulação, etc.).

O objetivo da estratégia é melhorar o resultado da empresa por meio das vantagens competitivas que, segundo Contador (2008), "é uma posição de superioridade reconhecida e valorizada pelo cliente que leva uma empresa a ser mais competitiva que uma concorrente ou a si mesma em momento anterior."

Um processo para formulação de estratégias competitivas consiste em métodos e procedimentos a serem seguidos para criar uma, a qual suportará o processo decisório dos altos executivos da organização. Segundo Silva (2008), este processo é suportado por modelos e metodologias que analisam os ambientes internos e externos da empresa, alinhando a operação de suas áreas à estratégia implantada. Um modelo que dá suporte a este processo é o MCAC apresentado no subitem a seguir.

\subsubsection{Modelo de campos e armas da competição}

Como visto anteriormente, uma técnica de administração estratégica é o modelo CAC, o qual prega que as empresas competem por meio de seus produtos. Segundo Contador (2008), neste modelo, os campos da competição representam a estratégia de posicionamento do produto no mercado. Isso consiste na definição de uma posição estratégica da empresa e do produto (ou família de produtos) ofertados no mercado, objetivando atender às exigências, necessidades, preferências, expectativas e/ou anseios dos clientes referentes a preço, produto, atendimento, prazo e imagem.

Esse modelo enquadra-se na área das estratégias competitivas, sendo associado à abordagem clássica de Whittington (2001), pois este entende a estratégia como um processo racional e deliberado que visa maximizar a vantagem em longo prazo. Além disso, ele pertence à Escola de Posicionamento de Mintzberg, Ahlstrand e Lampel (2000), por formular as estratégias competitivas por meio de um processo analítico e prescritivo, no qual a empresa se posiciona no mercado.

No modelo CAC, a metodologia não se aplica à formulação das estratégias corporativas e da indústria. A estratégia de negócio assume a forma de estratégia 
competitiva de negócio, cuja essência está na escolha dos campos da competição, aqueles no qual a empresa irá efetivamente obter vantagem competitiva, e dos coadjuvantes, campo auxiliar que complementa a estratégia competitiva de negócio contribuindo para o alcance e manutenção desta vantagem, para cada par produto/mercado. A decisão sobre a estratégia competitiva de negócio consiste na escolha de um ou dois campos principais, e de um ou dois campos coadjuvantes para cada par produto/mercado. É pela escolha de diferentes campos da competição que as empresas se diferenciam entre si (CONTADOR, 2008).

Campo da competição é um atributo de interesse do comprador, sendo o local imaginário da disputa entre as empresas pela preferência do cliente aos seus produtos (CONTADOR, 2008). No modelo CAC existem 14 campos da competição que são divididos em cinco grupos, denominados de macrocampos da competição, conforme a seguir: 


\begin{tabular}{|c|c|}
\hline Campos. & Significado \\
\hline \multicolumn{2}{|r|}{ Macrocampo Preço } \\
\hline Preço & Ter, ou almejar ter, preço menor do que o produto dos concorrentes. \\
\hline $\begin{array}{l}\text { Condições de } \\
\text { pagamento }\end{array}$ & $\begin{array}{l}\text { Oferecer, ou almejar oferecer, mais facilidades de pagamento que os } \\
\text { concorrentes, em termos de desconto, prazo, quantidade de parcelas de } \\
\text { pagamento e instrumento de crédito. }\end{array}$ \\
\hline $\begin{array}{l}\text { Prêmio e/ou } \\
\text { promoção }\end{array}$ & $\begin{array}{l}\text { Oferecer, ou almejar oferecer, temporariamente ao comprador, vantagens mais } \\
\text { interessantes que as dos concorrentes, como sorteios e ofertas, sem alterar o } \\
\text { preço normal de venda. }\end{array}$ \\
\hline \multicolumn{2}{|r|}{ Macrocampo Produto (bem ou serviço) } \\
\hline $\begin{array}{l}\text { Projeto do } \\
\text { produto }\end{array}$ & $\begin{array}{l}\text { Desenvolver, ou almejar desenvolver, produto com características e atributos } \\
\text { valorizados pelos clientes que atendam às suas exigências, necessidades, } \\
\text { preferências, expectativas ou anseios de forma mais atraente que as } \\
\text { características dos produtos concorrentes em termos de aparência visual, } \\
\text { funções a cumprir, facilidade de uso, qualidade dos materiais e do acabamento } \\
\text { e outros. }\end{array}$ \\
\hline $\begin{array}{l}\text { Qualidade do } \\
\text { produto }\end{array}$ & $\begin{array}{l}\text { Oferecer, ou almejar oferecer, produto que o cliente julgue de melhor qualidade } \\
\text { que a dos produtos concorrentes nos mais diversos critérios por ele valorizados, } \\
\text { como aparência visual, funções a cumprir, desempenho, facilidade de uso, } \\
\text { qualidade dos materiais e do acabamento, durabilidade e outros. }\end{array}$ \\
\hline Diversid & $\begin{array}{l}\begin{array}{l}\text { Oferecer, ou almejar oferecer, maior variedade de produtos que os } \\
\text { concorrentes. }\end{array} \\
\end{array}$ \\
\hline \multicolumn{2}{|r|}{ Macrocampo Atendimento } \\
\hline $\begin{array}{l}\text { Acesso ao } \\
\text { atendimento }\end{array}$ & $\begin{array}{l}\text { Proporcionar, ou almejar proporcionar, melhor acesso ao atendimento que o dos } \\
\text { concorrentes, sob o ponto de vista do cliente. }\end{array}$ \\
\hline $\begin{array}{l}\text { Projeto do } \\
\text { atendimento }\end{array}$ & $\begin{array}{l}\text { Desenvolver, ou almejar desenvolver, atendimento com características } \\
\text { valorizadas pelos clientes que atendam às suas exigências, necessidades, } \\
\text { preferências, expectativas e anseios de forma mais atraente que as } \\
\text { características dos concorrentes. }\end{array}$ \\
\hline $\begin{array}{l}\text { Qualidade do } \\
\text { atendimento }\end{array}$ & $\begin{array}{l}\text { Oferecer, ou almejar oferecer, atendimento que o comprador julgue de melhor } \\
\text { qualidade que a das empresas concorrentes. }\end{array}$ \\
\hline \multicolumn{2}{|r|}{ Macrocampo Prazo } \\
\hline $\begin{array}{l}\text { Prazo de en } \\
\text { do produto }\end{array}$ & $\begin{array}{l}\text { Ofertar, ou almejar ofertar, prazo de entrega do produto menor que o dos } \\
\text { concorrentes e conseguir cumprir o prazo negociado. }\end{array}$ \\
\hline Prazo de & Atender, ou almejar atender, o cliente em prazo menor que o dos concorrentes. \\
\hline \multicolumn{2}{|r|}{ Macrocampo Imagem } \\
\hline $\begin{array}{l}\text { Imagem do } \\
\text { produto e da } \\
\text { marca }\end{array}$ & $\begin{array}{l}\text { Oferecer, ou almejar oferecer, produto que o cliente julgue ter melhor imagem } \\
\text { do que os produtos concorrentes e possuir, ou almejar possuir, imagem crível } \\
\text { do produto e da marca mais favorável que a dos concorrentes, num aspecto } \\
\text { valorizado pelos clientes. }\end{array}$ \\
\hline $\begin{array}{l}\text { Imagem de } \\
\text { empresa confiável }\end{array}$ & $\begin{array}{l}\text { Possuir, ou almejar possuir, imagem crível mais favorável que a dos } \\
\text { concorrentes, num aspecto valorizado pelos clientes, funcionários, } \\
\text { fornecedores, membros da sociedade e acionistas e investidores. }\end{array}$ \\
\hline $\begin{array}{l}\text { Imagem em } \\
\text { responsabilidade } \\
\text { social }\end{array}$ & $\begin{array}{l}\text { Possuir, ou almejar possuir, imagem crível em responsabilidade social mais } \\
\text { favorável que a dos concorrentes, num aspecto valorizado pelo cliente. É } \\
\text { composto pela imagem cívica e imagem preservacionista. }\end{array}$ \\
\hline
\end{tabular}

Quadro 1 - Campos da competição

Fonte: Adaptado de Contador (2008)

A estratégia operacional/funcional assume a forma de estratégia competitiva operacional, que consiste na escolha das armas da competição a serem utilizadas 
pela empresa, determinando a intensidade de utilização de cada uma. Ela define as ações internas à empresa (CONTADOR, 2008).

Segundo Contador (2008), o modelo CAC trata igualmente os ambientes externos e internos. Os campos da competição retratam as possíveis posições de um produto no mercado, refletindo o ambiente externo da empresa. As armas da competição são os recursos e ações da empresa, refletindo seu ambiente interno.

Essas armas são classificadas, segundo sua natureza, em cinco categorias: planejamento; apoio; produção, atendimento e cooperação (utilizadas em alianças estratégicas). Além disso, elas também são classificadas, segundo sua relevância: em relevantes (arma pertencente ao conjunto das armas da empresa que proporciona elevada vantagem competitiva a ela no campo escolhido para competir), semi-relevantes (propicia mediana vantagem competitiva a ela no seu campo da competição e vantagem competitiva no seu campo coadjuvante) e irrelevantes (não proporciona vantagem competitiva a ela nem no seu campo da competição, nem no seu campo coadjuvante).

O grau de eficácia do uso dos recursos de uma arma e/ou de sua disseminação é conhecido como a intensidade em que esta é utilizada, caracterizando a intensidade de uma arma da competição.

A intermediação da relação entre campos e armas da competição é feita pelo alvo, o qual consiste nos objetivos que uma arma deve atingir (CONTADOR, 2008). Na Figura 3 é apresentada a interação do modelo.

\begin{tabular}{|c|c|c|c|}
\hline $\begin{array}{c}\text { Amar da aompeticáo } \\
\text { (origem das lo }\end{array}$ & $\begin{array}{c}\text { Alvos da amas } \\
\text { (indicadores desmpenho) }\end{array}$ & $\begin{array}{l}\text { Compos da competipato } \\
\text { (Nontagen competitiva) }\end{array}$ & $\begin{array}{l}\text { Grau de competitividade } \\
\text { (maicadores de resultado) }\end{array}$ \\
\hline 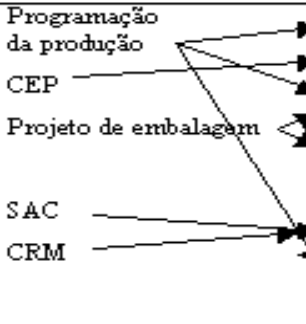 & $\begin{array}{l}\text { Produtividade } \\
\text { Quadidade no processo } \\
\text { Flexibilidade } \\
\text { Wovidade } \\
\text { Qual. no processer } \\
\text { Welocidade }\end{array}$ & 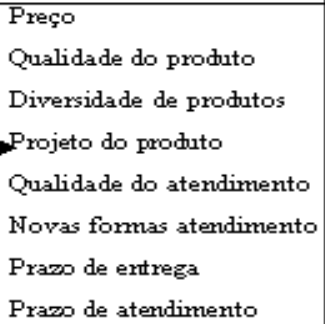 & 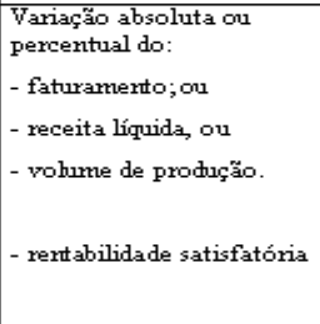 \\
\hline
\end{tabular}

Figura 3 - MCAC.

Fonte: Contador (2008) 


\section{REQUISITOS E FUNCIONALIDADES DO SISTEMA DE SUPORTE EXECUTIVO}

A especificação consiste na descrição sistemática do que este sistema deve fazer e quais suas propriedades funcionais. Já os requisitos são todas as funcionalidades estabelecidas pelo cliente. Ao se definir os requisitos, também já se definem quais serão as funções a serem validadas no produto (LEITE, 2006). Os requisitos e funcionalidades levantados, cuja validação da especificação dos requisitos foi realizada pelo idealizador do MCAC, são apresentados a seguir:

- Processo externo de apoio ao modelo: são identificadas a empresa, seus produtos e seus desempenhos. A soma dos desempenhos de cada produto da empresa gerará o desempenho global desta. Além disso, são identificados também os funcionários da empresa, incluindo seu(s) proprietário(s), e verificado se foi encontrada alguma oportunidade por este(s). Também é estimado o investimento em cada arma da competição da empresa e questionado se o(s) proprietário(s) aceita $(\mathrm{m})$ a estratégia competitiva sugerida pelo sistema.

- Delinear o negócio: neste processo é verificado a satisfação do(s) proprietário(s) com o desempenho global da empresa. Caso este(s) esteja(m) insatisfeito(s), será delineado o negócio da empresa, identificando o(s) objetivo(s) do(s) proprietário(s) e formulando a estratégia competitiva de negócio inicial da empresa.

- Estudar o segmento econômico ao qual a empresa pertence: neste processo são identificados os fornecedores e concorrentes com seus respectivos produtos, além dos clientes. Também é verificado quais campos da competição os concorrentes competem com seus produtos, através de pesquisa com funcionários da empresa e clientes, além dos campos da competição preferidos pelos clientes para cada par produto-mercado da empresa. Através das informações destas pesquisas é possível estudar o ambiente e monitorar os movimentos dos concorrentes e clientes. Se for 
verificado que o concorrente e/ou cliente mudaram seus campos da competição, ou seja, movimentaram-se, a estratégia competitiva da empresa será (re) formulada.

- Formular a Estratégia: neste processo são identificados os campos da competição da empresa para o par produto-mercado e suas armas, da competição ou não. Também são apresentados os campos da competição dos concorrentes, os preferidos pelos clientes e os adotados pela empresa para o par produto-mercado, além da classificação das armas da competição em relevantes, semi-relevantes e irrelevantes para cada campo da competição analisado - se mais de $35 \%$ das armas da competição forem classificadas como relevantes para o campo da competição, será preciso reclassificar as armas para o campo da competição analisado, pois os custos para implantação da estratégia serão altos. Este procedimento será feito para todos os pares produtos-mercado da empresa. Após classificar as armas da competição para todos os campos da competição preferidos pelos clientes, dos concorrentes e da empresa, será sugerida a estratégia operacional e verificada se mais de $60 \%$ das armas são relevantes. Caso forem, será preciso re-classificar as armas da competição da empresa para todos os campos da competição mencionados na pesquisa dos campos preferidos pelos clientes, dos concorrentes e empresa, e todos os pares produtomercado pesquisados, pois os custos para implantação desta estratégia operacional sugerida serão altos.

- Implantar a Estratégia: neste processo são executados os investimentos nas armas da competição da empresa, informando-o ao sistema.

\subsection{Fluxo de informações e modelagem de dados}

O fluxo de processos, apresentado na Figura 4, tem como objetivo mostrar os processos e subprocessos a serem executados em uma visão macro. Ele apresenta os procedimentos que deverão ser executados para formulação estruturada de uma 
estratégia competitiva. As funcionalidades do sistema proposto são apresentadas nos subitens a seguir:

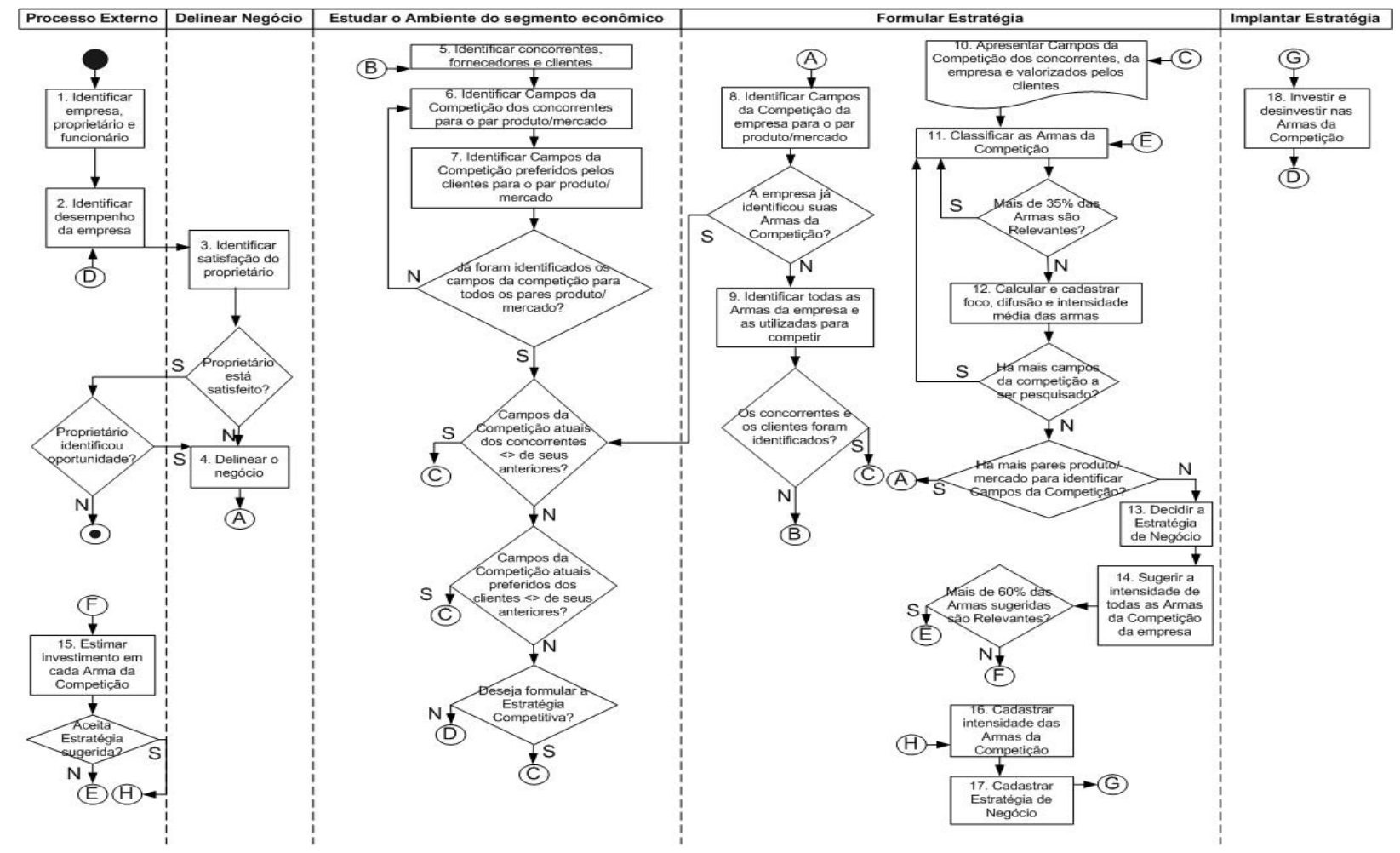

Figura 4 - Processo de formulação de estratégias para MPE's Fonte: Gomes (2007)

A seguir são apresentadas as funcionalidades de cada sub-processo do SSE:

1. Identificar empresa, proprietário e funcionário: cadastrar empresa, seus produto(s)/serviço(s), proprietário(s) e funcionário(s).

2. Identificar desempenho da empresa: consultar produto(s) da empresa e cadastrar dados do desempenho do(s) produto(s) da empresa.

3. Identificar satisfação do proprietário: identificar proprietário(s) e cadastrar satisfação do(s) Proprietário(s). Se houver mais de um proprietário, o sistema deverá verificar se a maioria simples (50\% mais 1) está ou não satisfeita com o desempenho da empresa.

4. Delinear o negócio: cadastrar o(s) objetivo(s) do(s) proprietário(s), os objetivos permanentes e formular a estratégia de negócio inicial para cada par produto/mercado. Formular a estratégia de negócio inicial para empresa 
consiste em identificar os campos da competição para cada par produto/mercado da empresa.

5. Identificar concorrentes, clientes e fornecedores: cadastrar concorrente(s), seus produto(s)/serviço(s); fornecedor(es) e seus produto(s)/serviço(s), além do(s) cliente(s).

6. Identificar campos da competição dos concorrentes para o par produto/mercado: cadastrar entrevistado, cadastrar produto(s)/serviço(s) e campos da competição do para cada par produto/mercado do concorrente. Para identificar os campos da competição dos pares produtos/mercados dos concorrentes, deve ser feita uma pesquisa de percepção, via solicitação de informações direta com o cliente e funcionários. Esta também poderá ser realizada através da disponibilização de um formulário de pesquisa para o cliente(s) e o funcionário(s) responder de acordo com sua percepção.

7. Identificar campos da competição preferidos pelos clientes para o par produto/mercado: cadastrar entrevistado, cadastrar produto(s)/serviço(s) e campos da competição do par produto/mercado preferidos pelos clientes. A pesquisa sobre os campos preferidos pelos clientes deve ser feita via solicitação de informações direta com estes ou através de um formulário de pesquisa para cada par produto/mercado da empresa.

8. Estudar o ambiente do segmento econômico: consultar campos da competição para cada par produto/mercado do(s) concorrente(s), os mais preferidos pelos clientes para cada par produto/mercado e os da empresa para cada par produto/mercado. Comparar os campos da competição da empresa com os mais utilizados pelo(s) concorrente(s) para cada par produto/mercado e comparar os campos da competição da empresa com os mais preferidos pelos clientes para cada par produto/mercado. Posteriormente ao cadastro das informações dos clientes, concorrentes e fornecedores, é feita uma pesquisa com os clientes e funcionários para identificar os campos da competição para cada par produto/mercado dos concorrentes e os preferidos pelos clientes para cada par produto/mercado da empresa. No processo de análise dos ambientes da indústria são pesquisadas informações sobre os clientes e os concorrentes. O sistema 
deverá estudar as informações de campos da competição mais utilizados pelo(s) concorrente(s) e mais preferidos pelo(s) cliente(s) para cada par produto/mercado visando verificar suas posições competitivas, e comparar com os campos da competição do(s) par(es) produto/mercado da empresa. Se na comparação entre os três campos atuais (competição, coadjuvante 1 e 2) escolhidos pelos concorrentes com os seus três primeiros campos anteriores no mesmo par produto/mercado forem diferentes, seja por opção ou por ordem de importância dos campos, o sistema deverá formular estratégias de negócio para a empresa. O mesmo ocorrerá se houver diferença entre os três campos atuais e os preferidos pelos clientes. A seleção dos campos da competição deve ser feita através das pesquisas realizadas de campos da competição sobre os concorrentes e os clientes para um mesmo par produto/mercado. Para contabilizar estes campos da competição, será preciso verificar o par produto/mercado em questão. Se ele for do concorrente, obviamente a pesquisa de campo da competição será sobre o concorrente em questão. Se for da própria empresa, a pesquisa será sobre o mais valorizado pelos clientes. A contabilização deve ser feita de modo a verificar quais foram os campos da competição citados na pesquisas e contabilizar quantas vezes cada um foi citado. O campo mais citado será considerado o campo da competição, o segundo mais citado será o coadjuvante 1, e o terceiro mais citado será o coadjuvante 2. Para comparar os campos da competição atuais dos concorrentes e preferidos pelos clientes com seus anteriores, é preciso selecionar a edição da pesquisa. Isto também serve para a comparação dos campos da competição escolhidos pela empresa com os dos concorrentes e preferidos pelos clientes. A seguir é apresentado como deverá ser feita a comparação dos campos da competição mais citados (respondidos) nas pesquisas para cada par produto/mercado dos concorrentes e preferidos pelos clientes com os da empresa:

- Selecionar os Campos da Competição atuais da empresa para todos os seus pares produto/mercado; 
- Selecionar os Campos da Competição atuais e anteriores, se houver, dos concorrentes e preferidos pelos clientes para todos os pares produto/mercado da empresa;

- Comparar os Campos da Competição atuais e anteriores, se houver, dos concorrentes para todos os pares produto/mercado da empresa. Se campos dos concorrentes diferentes de seus anteriores, apresentar os Campos da Competição dos concorrentes, da empresa e valorizados pelos clientes. Se forem iguais, perguntar se Campos da Competição preferidos pelos clientes são diferentes de seus anteriores;

- Comparar os Campos da Competição atuais e anteriores, se houver, valorizados pelos clientes para todos os pares produto/mercado da empresa. Se campos preferidos pelos clientes forem diferentes de seus anteriores, apresentar os Campos da Competição dos concorrentes, da empresa e valorizados pelos clientes. Se forem iguais, perguntar ao(s) proprietário(s) se deseja $(\mathrm{m})$ formular a estratégia competitiva da empresa. Caso deseje $(\mathrm{m})$ formular a estratégia competitiva, apresentar os Campos da Competição dos concorrentes, da empresa e valorizados pelos clientes. Se não desejar(em) formular a estratégia competitiva, ele(s) deve $(m)$ identificar o desempenho da empresa.

\section{Identificar campos da competição da empresa para o par} produto/mercado: cadastrar respondente; cadastrar produto e cadastrar campos da competição do produto da empresa. A pesquisa de campos da competição para cada par produto/mercado da empresa será feita no delineamento do negócio da empresa feita pelo(s) proprietário(s). Os respondentes destas pesquisas são os funcionários da empresa e os proprietários, cuja seleção dos Campos da Competição para cada par produto/mercado da empresa será os três primeiros Campos da Competição mais citados nestas pesquisas para um mesmo par produto/mercado, sendo 0 primeiro mais citado o principal, o segundo mais citado o coadjuvante hum e 0 terceiro mais citado o coadjuvante dois. 
10.Identificar todas as armas da empresa e as utilizadas para competir: identificar armas; cadastrar armas e informar se a arma é da competição ou não. Nesta fase são identificadas, pelo(s) proprietário(s) ou por um proposto, as armas da empresa. Essa relação deve conter de $80 \%$ a $90 \%$ das armas utilizadas pela empresa. As outras $10 \%$ ou $20 \%$ podem ser específicas do segmento econômico ou da empresa. Da relação de armas utilizadas pela empresa (as $80 \%$ ou $90 \%$ ), o(s) proprietário(s) ou um proposto deverá selecionar de 40 a 60 armas mais frequentemente utilizadas pela empresa. Essas 40 a 60 serão identificadas como armas da competição.

11. Apresentar campos da competição dos concorrentes, da empresa e valorizados pelos clientes: identificar concorrente; identificar empresa; identificar cliente; identificar produto do concorrente; identificar produto da empresa; identificar campos da competição para o par produto mercado do concorrente; identificar campos da competição para o par produto mercado da empresa; identificar campos da competição para o par produto mercado da empresa preferidos pelos clientes e apresentar campos da competição dos concorrentes, da empresa e preferidos pelos clientes para todos os pares produto/mercado. Nesta etapa são apresentados os campos da competição e coadjuvantes 1 e 2 (mais citados na pesquisa de campos da competição para o par produto mercado) dos concorrentes, da empresa e preferidos pelos clientes.

12. Classificar as armas da competição: informar campo da competição; informar, classificar e caracterizar arma da competição. Nesta etapa são classificadas as armas da competição da empresa em relevante, semirelevante e irrelevante para cada campo da competição.

13.Calcular e cadastrar foco, difusão e intensidade média das armas: calcular foco; calcular difusão; calcular intensidade média das armas; cadastrar foco; cadastrar difusão e cadastrar intensidade média das armas. Para calcular o foco, difusão e intensidade média das armas o sistema deverá seguir as seguintes fórmulas: Foco = Soma da pontuação do Foco / (Número de Armas Relevantes * 5); Difusão = Soma da pontuação da Difusão / 
(Número de Armas Irrelevantes * 5); e Intensidade Média = Soma da Intensidade / Número de Armas da Competição.

14. Decidir a estratégia de negócio: para se cadastrar a estratégia de negócio é preciso antes sugeri-la ao(s) proprietário(s). Para sugerir a estratégia de negócio, é preciso seguir as seguintes diretrizes:

- Escolher campos na mesma ordem daqueles valorizados pelos clientes;

- Escolher campos de forma a obedecer à ordem decrescente dos focos;

- Escolher campos que possuam alto foco e baixa difusão;

- Procurar evitar campos que sejam incompatíveis entre si, como preço e prazo de entrega, ou preço e qualidade, ou qualidade e prazo, pois esses campos exigem o uso de uma mesma arma com alvos diferentes. Havendo dois alvos incompatíveis, não é possível aperfeiçoá-los; e

- Levar em consideração os campos onde os concorrentes competem.

Para sugerir a estratégia de negócio, o sistema deverá executar o seguinte procedimento que foi estabelecido em conjunto com Contador (1996):

1. Se o foco do $1^{\circ} \mathrm{Campo}$ da Competição mais citados pelos clientes para o par produto/mercado for maior ou igual a 0,7 e este campo da competição for diferente do $1^{\circ}$ Campo da Competição do concorrente para o mesmo par produto/mercado, sugerir este campo como $1^{\circ}$ Campo da Competição da empresa. Caso contrário, questionar se o(s) proprietário(s) deseja(m) competir neste campo. Se ele(s) não quiser(em) competir, sugerir o $1^{\circ} \mathrm{Campo}$ da Competição escolhido pelo(s) proprietário(s) para empresa. Senão, sugerir o $1^{\circ} \mathrm{Campo}$ da Competição mais citados pelos cliente s;

2. Se foco do $2^{\circ} \mathrm{Campo}$ da Competição mais citados p elos clientes para o par produto/mercado for maior ou igual a 0,6 e este campo da competição for diferente do $2^{\circ}$ Campo da Competição do concorrente para o mesmo par produto/mercado, sugerir este campo como $2^{\circ}$ Campo da Competição da empresa. Caso contrário, perguntar se o(s) proprietário(s) deseja $(\mathrm{m})$ competir neste campo. Se ele(s) não quiser(em) competir, sugerir o $2^{\circ}$ Campo da 
Competição escolhido pelo(s) proprietário(s) para empresa. Senão, sugerir o $2^{\circ}$ Campo da Competição mais citados pelos clientes;

3. Se foco do $3^{\circ} \mathrm{Campo}$ da Competição mais citados pelos clientes para o par produto/mercado for maior ou igual a 0,5 e este campo da competição for diferente do $3^{\circ}$ Campo da Competição do concorrente para o mesmo par produto/mercado, sugerir este campo como $3^{\circ}$ Campo da Competição da empresa. Caso contrário, perguntar se o(s) proprietário(s) deseja(m) competir neste campo. Se ele(s) não quiser(em) competir, sugerir o $2^{\circ}$ Campo da Competição escolhido pelo(s) proprietário(s) para empresa. Senão, sugerir o $3^{\circ}$ Campo da Competição mais citados pelos clientes.

15. Estimar investimento em cada arma da competição: para estimar o valor a ser investido em cada arma, o(s) proprietário(s) pode $(\mathrm{m})$ se encarregar(em) desta atividade ou designar um funcionário para fazer isso. Para estimar estes investimentos, será necessário desenvolver um projeto. O consolidado de todos os projetos de investimentos de todas as armas gerará o plano de investimentos global da empresa. Este processo de estimativa de investimento em cada arma da competição é externo ao processo de formulação de estratégias competitivas. Os procedimentos para sua execução e implementação ficarão a cargo do executor.

16.Sugerir intensidade de todas as armas da competição da empresa: nesta etapa o sistema sugere a intensidade de todas as armas da competição da empresa, baseando na classificação das 40 a 60 armas da competição em Relevante, Semi-Relevante e Irrelevante para cada campo da competição escolhido pela empresa, feita pelo(s) proprietários em cada par produto/mercado. A intensidade de uma arma varia em função do campo ser da competição ou coadjuvante, pois uma mesma pode ser relevante para um campo e irrelevante para outro. Na Tabela 2, é apresentada a regra de sugestão de intensidade de uma mesma arma da competição em um mesmo par produto/mercado para os três campos da competição escolhidos pela empresa: 
Tabela 2 - Recomendação da intensidade de uma mesma arma

\begin{tabular}{|l|l|l|c|}
\hline Primeiro campo & \multicolumn{1}{|c|}{ Segundo campo } & Terceiro campo & Intensidade da arma \\
\hline Relevante & Relevante & Relevante & 5 \\
\hline Relevante & Relevante & Semi-relevante & 5 \\
\hline Relevante & Relevante & Irrelevante & 5 \\
\hline Relevante & Semi-relevante & Relevante & 5 \\
\hline Relevante & Semi-relevante & Semi-relevante & 5 \\
\hline Relevante & Semi-relevante & Irrelevante & 5 \\
\hline Relevante & Irrelevante & Relevante & 4 \\
\hline Relevante & Irrelevante & Semi-relevante & 4 \\
\hline Relevante & Irrelevante & Irrelevante & 4 \\
\hline Semi-relevante & Relevante & Relevante & 4 \\
\hline Semi-relevante & Relevante & Semi-relevante & 4 \\
\hline Semi-relevante & Relevante & Irrelevante & 4 \\
\hline Semi-relevante & Semi-relevante & Relevante & 3 \\
\hline Semi-relevante & Semi-relevante & Semi-relevante & 3 \\
\hline Semi-relevante & Semi-relevante & Irrelevante & 3 \\
\hline Semi-relevante & Irrelevante & Relevante & 3 \\
\hline Semi-relevante & Irrelevante & Semi-relevante & 2 \\
\hline Semi-relevante & Irrelevante & Irrelevante & 2 \\
\hline Irrelevante & Relevante & Relevante & 3 \\
\hline Irrelevante & Relevante & Semi-relevante & 3 \\
\hline Irrelevante & Relevante & Irrelevante & 3 \\
\hline Irrelevante & Semi-relevante & Relevante & 2 \\
\hline Irrelevante & Semi-relevante & Semi-relevante & 1 \\
\hline Irrelevante & Semi-relevante & Irrelevante & 1 \\
\hline Irrelevante & Irrelevante & Relevante & 2 \\
\hline Irrelevante & Irrelevante & Semi-relevante & 1 \\
\hline Irrelevante & Irrelevante & Irrelevante & 1 \\
\hline Fone: Adapado & & & \\
\hline
\end{tabular}

Fonte: Adaptado de Contador (2008).

17. Cadastrar intensidade das armas da competição: identificar a arma e cadastrar a intensidade. Após a estratégia competitiva ter sido aceita, 0 sistema deverá atualizar as intensidades das armas da competição da empresa.

18.Cadastrar estratégia de negócio: cadastrar os dados da Estratégia de Negócio.

19. Investir e "desinvestir" nas armas da competição: Identificar a arma da competição da empresa e cadastrar os investimentos e desinvestimentos a serem feitos na arma da competição da empresa. 
Por meio do estudo do processo, especificou-se as seguintes tabelas: Campos da Competição - cadastro de todos os campos da competição; Armas da Competição - cadastro de todas as armas da competição do modelo; Pessoa cadastro de Pessoa; Produto/Serviço - cadastro de todos os produtos; Desempenho - cadastro do desempenho da empresa por produto (a partir dos dados contidos nesta tabela, o qual é mensurado por produto da empresa, é possível gerar informações contendo os dados do desempenho global da empresa, que se dará pelos resultados acumulados de seus produtos); Pesquisa - cadastro da pesquisa de campos da competição; Arma da Pessoa - cadastro das armas utilizadas pela empresa; Estratégia de Negócio - cadastro da estratégia de negócio; Armas Analisadas - cadastro de armas analisadas pelo usuário; Armas Sugeridas cadastro de intensidades sugeridas pelo software; e Resultado de análise - cadastro do resultado da análise das armas da competição.

Com as tabelas especificadas, foi possível gerar o MER (Modelo de Entidade e Relacionamento), que consiste em uma expressão gráfica da estrutura lógica do banco de dados. Uma entidade é um ou mais objetos do mundo real como, por exemplo, produto. Já o relacionamento é a junção de uma ou várias entidades (SILBERSCHATZ ET AL, 1999). Na Figura 5 é apresentado o MER do sistema proposto: 


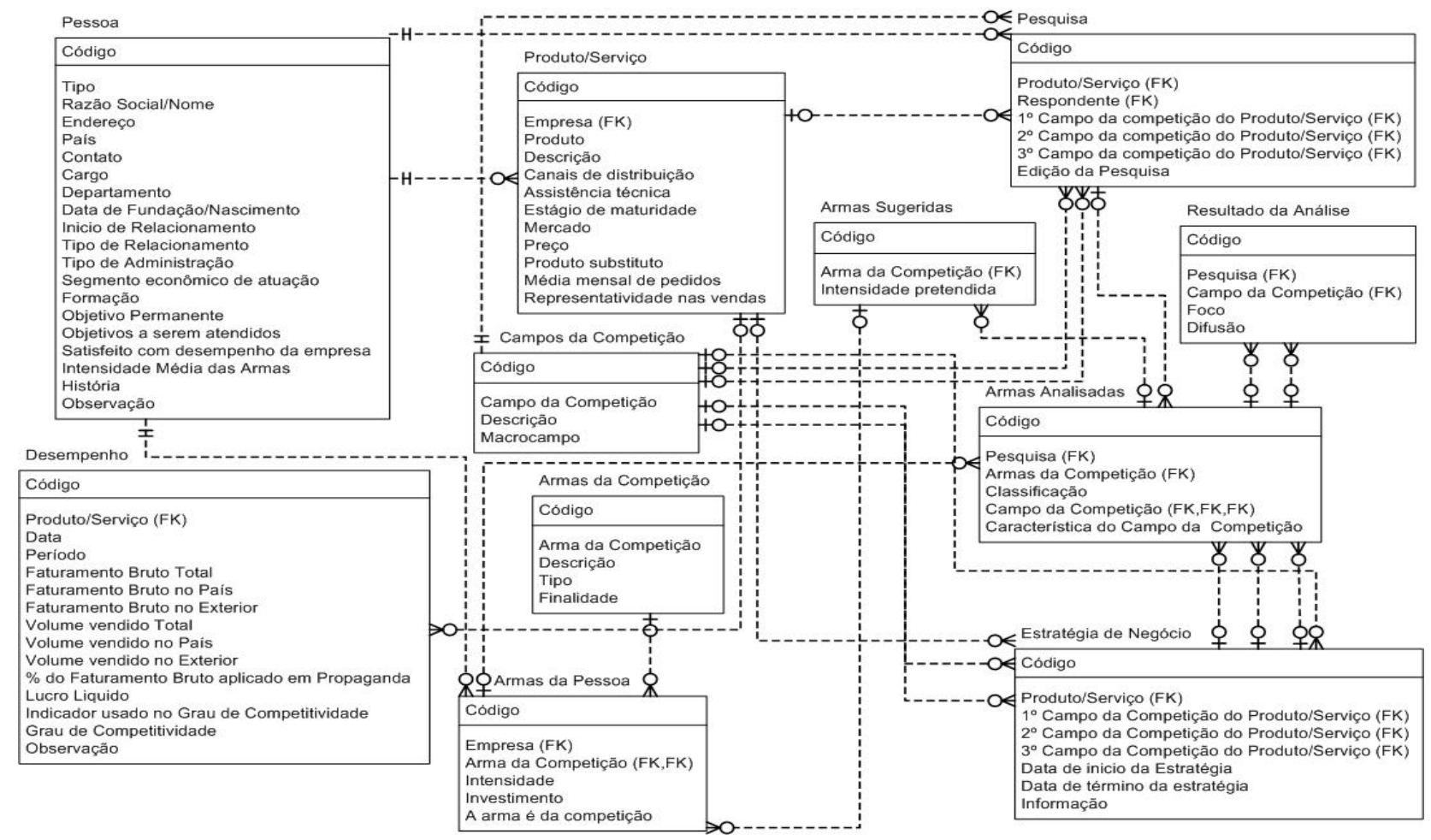

Figura 5 - MER do sistema ${ }^{1}$

Fonte: Gomes (2007)

Segundo Modell (1996), existem três tipos de projetos para se desenvolver um SI: manual; manual para automático e re-automação. O manual consiste na formalização, por meio de documentação e padrões, de processos adotados ou a serem adotados, visando atender as necessidades da empresa, não sendo transformados em programas de computador. O manual para automático exige a criação de um modelo computacional o qual possa ser utilizado pelo desenvolvedor, além das atividades do tipo anterior. Por fim, a re-automação possui uma base a qual pode ser utilizada como referência do que deve ser feito, mantido e das novas atividades necessárias. Neste artigo, foi desenvolvido um projeto manual de SSE.

\section{CONCLUSÃO E RECOMENDAÇÕES}

Para atender a necessidade dos dirigentes de MPE's para formularem estratégias competitivas de suas empresas, formalizando este tipo de administração em suas organizações, foi apresentada uma especificação de um SSE que oriente a

\footnotetext{
${ }^{1}$ FK (Foreign Key): chave estrangeira utilizada para indicar relacionamento com outra tabela.
} 
formulação de estratégias competitivas, através da sugestão de alternativas, a qual uma deverá ser escolhida pelo(s) dirigente(s) dessa(s) empresa(s) para ser implantada em sua organização.

Conforme Contador (2008), a maioria das informações, que deverão ser utilizadas para alimentar o sistema, estão disponíveis na própria empresa através da sua relação com clientes e fornecedores, os quais também conhecem os concorrentes e que podem ser utilizados como fontes de informações sobre eles. Ocorrendo fatos novos no ambiente provenientes de clientes, concorrentes, fornecedores, entre outros, as informações constantes no sistema deverão ser atualizadas.

Referente a este artigo, uma de suas limitações foi não haver tempo hábil para desenvolver um modelo computacional a partir do sistema proposto. Isso fica como recomendação para o desenvolvimento de futuros trabalhos, pois o MER do sistema e seus fluxos e regras de informações foram apresentados, ficando a cargo do desenvolvedor escolher as soluções tecnológicas que melhor lhe convier, pois não existem restrições para isso.

\section{REFERÊNCIAS}

BETIM, L. M.; RESENDE, L. M.; SCANDELARI, L.; KOVALESKI, J. L. Uso da informatização e realização dos controles de gestão: estudo em PE's do setor madereiro de um distrito industrial. ENCONTRO NACIONAL DE ENGENHARIA DE PRODUÇÃO. 25. 2005. Anais... Porto Alegre, 2005.

CARVALHO, A. M. R.; CHIOSSI, T. C. S.; RUBIRA, C. M. F. Introdução à engenharia de software. Campinas: Instituto de Computação da Universidade Estadual de Campinas, 2007.

CONTADOR, J. C. Modelo para aumentar a competitividade industrial: a transição para a gestão participativa. São Paulo: Edgard Blücher, 1996.

Campos e armas da competição: novo modelo de estratégia. 1.ed. São Paulo: Saint Paul, 2008.

GOMES, L. S. Micro e pequenas empresas: especificações dos requisitos funcionais de um software para formulação estruturada de estratégias competitivas fundamentada no modelo de campos e armas da competição. 2007. Dissertação (Mestrado) - UNINOVE, São Paulo, 2007. 
KOTHA, S; ORNE, D. Generic Manufacturing strategies: a conceptual synthesis. Strategic Management Journal, v.10, n.3, p. 211-231, 1989.

LAUDON, K.; LAUDON, J. Essentials of Management Information Systems. New Jersey, Prentice Hall, 2001.

LEITE, J. C. Análise e especificação de requisitos. Disponível em: <http://www.dimap.ufrn.br/ jair/ES/es991c3.htm>. Acesso em: 27 nov. 2006.

MACEDO, N. D. Iniciação à pesquisa bibliográfica: guia do estudante para a fundamentação do trabalho de pesquisa. 2. ed. São Paulo: Edições Loyola, 1994.

MINTZBERG, H. Designing effective organizations. New Jersey: Prentice Hall, 1983.

MINTZBERG, H.; AHLSTRAND, B.; LAMPEL, J. Safári de estratégia: um roteiro pela selva do planejamento estratégico. Porto Alegre: Bookman, 2000.

MODELL, M. E. A Professional's guide to systems analysis. 2. ed. New York: McGraw Hill, 1996.

PRESSMAN, R. Engenharia de software. São Paulo: Makron Books, 1995.

REZENDE, D. A. Tecnologia da informação integrada à inteligência competitiva: alinhamento estratégico e análise da prática nas organizações. São Paulo: Atlas, 2002.

SILBERSCHATZ, A.; KORTH, H. F.; SUDARSHAN, S. Sistemas de banco de dados. 3. ed. São Paulo: Makron Books, 1999.

SILVA, E. M. O relacionamento entre estratégias de manufatura, práticas de produção e desempenho operacional e de negócio: um survey em firmas do setor moveleiro. Tese. (Doutorado) - Universidade de São Paulo. São Carlos, 2008.

SILVA, F. R. O desenvolvimento de sistemas da informação como campo privativo do administrador. Disponível em:

<http://www.craes.org.br/doc/artigos/Artigo\%20de\%20Felipe\%20Rodrigues 17.pdf>. Acesso em: 20 nov. 2009.

SWAMIDASS, P. M.; NEWELL, W. T. Manufacturing strategy, environmental uncertainty and performance: a path analytic model. Management science, v. 33, n. 4, 1987.

WHITTINGTON, R. Learning to strategise: problems of practice. Oxford, Skope Research Paper, 2001. 
ZANON, J. C.; FILHO, A. G. A. Consenso estratégico: um estudo de caso sobre percepções de gerentes a respeito das prioridades competitivas das operações. SIMPÓSIO DE ADMINISTRAÇÃO DA PRODUÇÃO, LOGÍSTICA E OPERAÇÕES INTERNACIONAIS. 11. 2008. Anais. São Paulo, 2008.

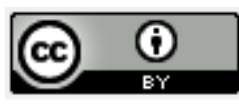

Artigo recebido em 14/12/2009 e aceito para publicação em 12/08/2010. 